\title{
O livro dos guerrilheiros, de Luandino Vieira: as vidas valerosas e mortes exemplares de seus guerrilheiros-andantes
}

Luiz Maria Veiga

Universidade de São Paulo

á, em O livro dos rios, primeiro romance do ciclo chamado De rios velhos e guerrilheiros, passagem em que um grupo de combatentes nacionalistas está reunido para julgar por traição um ex-camarada. Kene Vua, o narrador, nomeia os presentes. Entre eles:

o monitor político Celestinho Mbaxi, o que em traidição nossa era o nosso querido camarada Kakinda Bastião". E ainda: o "Makongo, dito o Mau-dosMaus, pambala, um menino pioneiro de maldades; luz de brasa debaixo da cinza, a caradura do Kizuua-Kiezabu; Kibiaka, o parabelo, pássaro traquino; o Farrapado e o camarada Kadisu como que falavam calados lá na vida deles, sentados juntos (Vieira, 2006, p. 38-39).

Pois é em torno de cada um desses guerrilheiros que serão construídas as cinco narrativas que, reunidas a um texto de abertura e a uma espécie de epílogo, vão compor este tão sui-generis romance, que de modo algum pode ser considerado em outra categoria, visto que é a segunda parte de, como já dissemos, um romance cíclico. Ao primeiro guerrilheiro corresponde a primeira narrativa, sob o título: "Celestino Sebastião (Kakinda), de Tenda Rialozo". Ao segundo, a segunda narrativa: "Eme Makongo, Mau Pássaro, o Mau-dosMaus". Ao terceiro, corresponde a quinta narrativa: "Kizuua Kiezabu, nosso general Kimbalanganza". O quarto guerrilheiro, personagem conhecido dos leitores de Nós, os do Makulusu, aparece na terceira narrativa: "Kibiaka, a quem chamavam o Parabelo". E aos quinto e sexto guerrilheiros, que agiam como se fossem um só, corresponde a quarta narrativa: "Zapata, melhor dizendo: Ferrujado e Kadisu". 
Mas o leitor, diante da afirmação que diz ser O livro dos guerrilheiros um romance, poderia perguntar: se é assim por que encontramos, abaixo do título, na capa e na página de rosto, a indicação "_ narrativas -"? É provável que seja porque, mais uma vez, o autor quis jogar com seu público, dando-lhe mais que um texto a ler: propondo enigmas a decifrar e desvendar. Em nota assinada por Andrea S. Sanches e publicada num semanário angolano (Novo Jornal, n. 90, de 9/10/2009, p. 15), com os títulos "Luandino Vieira com novo livro" e "Memórias fictícias de um ex-guerrilheiro", o próprio autor dá instruções de como se aproximar do texto, diz que o livro "deve ser lido devagar pois exige um grande esforço de interpretação".

$\mathrm{Na}$ primeira parte do texto, chamada "EU, OS GUERRILHEIROS", e que funciona como introdução, há uma espécie de proposta-sumário da obra, assim mesmo, toda em maiúsculas:

pauta de alguns guerrilheiros que teve no grupo do comandante ndiki ndia, ou andiki, e que vieram na missão que fomos no kalongololo, naquele ano de 1971. conforme notícias, mujimbos e mucandas e ainda as lembranças de quem lhes escreveu. alguns sucedos de suas valerosas vidas ou de suas exemplares mortes, para alegria dos menores e tristura dos mais-velhos. (p. 9 - cit. identif. apenas por número da página referem-se à obra resenhada)

O título já estabelece a integração entre o individual ("EU”), representado pelo, ao mesmo tempo, narrador, relator, depositário (das mucandas, ou seja, dos papéis, dos documentos) e organizador das narrativas, nosso já conhecido Kene Vua, e o corpo coletivo ("OS GUERRILHEIROS") de que ele faz parte. Nesta proposta-sumário está mencionada a ação que unifica e reúne as "narrativas" aparentemente desligadas e que é "a missão que fomos no Kalongololo, naquele ano de 1971", além de evocar as velhas canções de gesta dos cavaleiros andantes ("sucedos de suas valerosas vidas ou de suas exemplares mortes") e dar uma direção, propor um sentido a tal celebração de memórias ("para alegria dos menores e tristura dos mais-velhos"). $\mathrm{Na}$ abertura da primeira narrativa, que trata de Celestino Sebastião, dito Kakinda, também se pode notar um eco das velhas epopeias clássicas: "Cantarei o herói, o que sempre exemplificou seu povo, vida e morte e luta, o dos cinco combates" (p. 13). 
Tudo isso acentua (e o leitor há de notá-lo) o domínio, o engenho e a arte do autor (estamos nos referindo ao autor explícito) ao lidar com a linguagem e com a construção literária. Ao mesmo tempo em que simula a escrita de um narrador pouco instruído, que se põe à parte dos "verdadeiros escritores da nossa terra" para dizer que a verdade está "cadavez apenas nas estórias que contamos uns nos outros, enquanto esperamos nossa vez na fila de dar baixa de nossas pequeninas vidas" (p. 12), pontua seu texto de referências intertextuais que de novo desafiam a capacidade e a argúcia do leitor para descobrir o que há a mais no texto, o que está sendo evocado, toda uma herança de cultura universal (e contemporânea, e local) que ali reverbera e ecoa.

A ficção se desdobra em novos níveis quando surgem, em algumas passagens, notas que parecem ser do autor explícito explicando passagens das narrativas de Kene Vua, referindo-se a diálogos do "autor" com ele, narrador, mas que são na verdade mais elementos ficcionais do texto. É o caso da nota em que "o autor", ao ouvir a narrativa sobre Kibiaka, dito o Parabelo, mostra ao narrador trechos do romance Nós, os do Makulusu em que aparece a figura desse mesmo Kibiaka, e como ele adquiriu a arma, uma pistola parabellum (presente do personagem Mais-Velho quando Kibiaka foi reunir-se aos guerrilheiros na mata) que acabaria por lhe valer o zombeteiro epíteto, mencionado apenas pelas costas do nomeado, já que ele dedicava muito tempo e cuidado à limpeza de uma arma para a qual não dispunha nem podia conseguir munição. Ora, nessa nota (p. 53) fica dito pelo "autor" que aquele personagem, Kibiaka, lhe aparecia em sonhos quando ele estava redigindo o romance, e que foi a partir desses sonhos que ele veio a figurar na obra escrita em 1967. Haveria então algo de maravilhoso naqueles sonhos, que antecipariam o conhecimento de uma figura real de que ele ouviria falar muito mais tarde. Tudo isso é ficção e seus espelhamentos, pois Luandino Vieira, em entrevista famosa dada a Michel Laban em 1977, declara (e presumimos que estivesse, nesse depoimento, revelando passagens verdadeiras de sua vida ao entrevistador): "Kibiaka é um companheiro meu de escola cuja alcunha era realmente Kibiaka e que se chamava - era um menino muito escuro -, chamava-se Tristão. Nunca mais o vi, não sei o que foi feito dele, desde os tempos da escola..." (Laban, 1980, p. 41). Isso nos faz lembrar que diante de um texto literário, ficcional, não devemos nunca perder de vista que estamos lidando com uma espécie de mentiroso profissional, e que a ficção só tem compromisso com a "verdade" que ela mesma cria. 
Além do diálogo com a própria obra, Luandino também dialoga com outros escritores angolanos. Há, neste ciclo de romances, neste narrador Kene Vua, algo que lembra o estilo narrativo de Agostinho André Mendes de Carvalho, mais conhecido como Uanhenga Xitu. E a dedicatória "À memória de José Mendes de Carvalho Comandante Hoji ia Henda (1941-1968)" (p. 7), irmão do escritor, só faz acentuar nossa suspeita. E há referência explícita a um outro escritor angolano, que seria amigo do narrador, "o tal escritor meu amigo, o Manel Rui” (p. 93), evocado quando Kene Vua encontra um de seus ex-companheiros de guerrilha, Kizuua Kiezabu. Mas agora, vinte anos depois daquela missão no Kalongololo, ele é o general Kimbalanganza, e está a bordo de iate de sua propriedade, enquanto Kene Vua ximbica uma simples chata na travessia para o Mussulo. Lembrando uma reflexão de Noíto, personagem de Rioseco, romance de Manuel Rui, que também se passa no Mussulo, reflexão em que ela evoca o atual estado de um antigo comandante guerrilheiro ("Deve estar muito rico. Afinal, lutámos para ele ficar rico. Se calhar não podiam ficar todos. É por isso. Uns ficaram ricos, outros ficaram pobres e sem pernas" (Rui, 1997, p. 335). Kene Vua tem, com seu ex-companheiros de armas, um diálogo assemelhado. Do alto da amurada de seu iate o general diz ao ex-guerrilheiro: “- Não tens vergonha de andar numa chata?!... / - Tenho! - disse eu. - Mas é pró camarada general andar de iate. Senão, não dava!... O mar não cabia para os dois...” (p. 92).

Muito mais haveria a dizer sobre este curto, conciso, enxuto romance, que se desdobra e desdobra em significados, sobre o passado e sobre o presente da nação angolana. O pequeno diálogo entre Kene Vua e o general Kimbalanganza, acima reproduzido, já é uma expressiva indicação de como estão errados os que muitas vezes perguntam a Luandino porque ele não trata, em sua ficção, da atual conjuntura angolana, parecendo preferir refugiar-se no passado. Acontece que ele trata da atual conjuntura angolana, e não é apenas na passagem acima indicada. Mas é preciso ter olhos para ler e ouvidos para ouvir ou, como ele mesmo diz, é preciso ler devagar e muitas vezes, é preciso participar ativamente da obra, fazendo "um grande esforço de interpretação". 


\section{Referência Bibliográfica}

LABAN, Michel. "Encontros com Luandino Vieira, em Luanda” In LABAN, Michel et alli. Luandino José Luandino Vieira e a sua obra (estudos, testemunhos, entrevistas). Lisboa: Edições 70, 1980, p. 9-82.

RUI, Manuel. Rioseco. Lisboa: Cotovia, 1997.

VIEIRA, José Luandino. O livro dos rios. De rios velhos e guerrilheiros I. Lisboa: Caminho, 2006. 